\title{
Mobbing'in Örgüte Bağlılığa ve Yöneticiye Güvene Etkisi
}

\begin{abstract}
Çalışmanın amacı, iş yerlerinde maruz kalınan mobbingin örgüte bağlılığa (duygusal bağlılık, devam bağlılığı, normatif bağlılık) ve yöneticiye olan güvene etkisini araştırmaktır. Bu amaç doğrultusunda, toplam 244 katılımcıdan anket yöntemiyle veri toplanmıştır. Çalışmanın örneklemini "basit tesadüfi örneklem" yöntemiyle seçilen, 7 ildeki (İstanbul, Bursa, Ankara, Antalya, İzmir, Konya, Hatay) eğitimciler oluşturmaktadır. Çalışmada toplanan veriler SPSS 23.0 istatistik programı ile analiz edilerek, elde edilen bulgular yorumlanmıştır. Normal dağılıma uygun olduğu tespit edilen verilere, geçerlilik ve güvenilirlik analizleri ile korelasyon ve regresyon analizleri uygulanmıştır. Gerçekleştirilen analizler neticesinde; mobbingin hem örgüte bağ|ılığın alt boyutlarından olan duygusal bağlılık ve normatif bağlılık ile hem de yöneticiye güven ile istatistiki olarak anlamlı ve negatif ilişkisinin olduğu tespit edilmiştir.
\end{abstract}

Anahtar Kelimeler: Mobbing, Yöneticiye Güven, Duygusal Bağııık, Devam Bağlılığı, Normatif Bağlılık
Gülay Murat ${ }^{1}$

Meral Elçi ${ }^{2}$

The Effect of Mobbing on Organizational Commitment and Trust in Manager

\begin{abstract}
The aim of the study was to investigate the effect of mobbing in the workplace on the commitment to the organization (affective commitment, continuance commitment, normative commitment) and trust in the manager. For this purpose, data were collected from a total of 244 participants by survey method. The sample of the study consists of educators in 7 (İstanbul, Bursa, Ankara, Antalya, İzmir, Konya, Hatay) provinces. The data collected in the study were analyzed with the SPSS 23.0 statistical program and the findings were interpreted. The data determined to be suitable for normal distribution; validity analysis, reliability analysis, correlation analysis, and regression analysis were applied. As a result of the regression analysis, it was found that mobbing has a statistically significant and negative relationships with the affective commitment and normative commitment, which is one of the sub-dimensions of organizational commitment and trust to the manager.
\end{abstract}

Keywords: Mobbing, Trust in Manager, Affective Commitment, Continuance Commitment, Normative Commitment

\section{Giriş}

Günümüzde örgütsel hedeflere ulaşmak için en önemli husus, iyi yapılandırılmış bir organizasyona sahip olmaktır. Dahası, örgütler kalıcılığını korumak için, kurum kültürü ve değerleri ışığında güçlü bir yapıya, misyon ve vizyona sahip olmalı, nitelikli işgörenlerle çalışarak yüksek performans göstermelidir. Öte yandan, kuruluşun başarısı, üretim faktörleri arasında en önemli yere sahip olan "insan" faktörü ile ilgilidir (Koç ve Kurtbaş, 2011: 16). Çalışanların, yüksek performans göstermesi de, motive olmalarıyla doğru orantılıdır. Organizasyonlarda gerçekleşen mobbing davranışları ise çalışanların motivasyonlarını düşürerek, örgüte olan bağlılıklarını olumsuz olarak etkilemektedir (Bedük ve Yıldız, 2016: 77).

Örgütte gerilime ve çatışma iklimine yol açan faktörlerin birleşimiyle ortaya çıkan ve örgüt sağlığını bozarak aynı zamanda çalışma barışını da engelleyen ciddi bir sorun olan mobbing; örgüt içerisindeki çalışanların başka bireyi ya da bireyleri rahatsız ettiği ve ahlak dışı olarak gerçekleşen sistematik bir süreçtir (Tetik, 2010: 81). Mobbingin gerçekleştiği örgütlerde, çalışanlar örgüte karşı güven ve bağlanma hislerini kaybetmektedirler (Tutar, 2004: 101). Mobbingin, kişi

\footnotetext{
${ }^{1}$ Arş. Gör. , Gebze Teknik Üniversitesi İşletme Fakültesi, İşletme Bölümü. gulaymurat@gtu.edu.tr, Yazar ORCID bilgisi: 0000-0003-2444-6608.

${ }^{2}$ Doç. Dr., Gebze Teknik Üniversitesi İşletme Fakültesi, İşletme Bölümü. emeral@gtu.edu.tr, Yazar ORCID bilgisi: 00000002-0547-0250
} 
üzerinde olduğu kadar örgüt üzerinde de negatif etkileri vardır. Yönetici açısından ortaya çıkan sorunlar ilk olarak ekonomik nitelikte olabilir. Fakat bununla birlikte ağır sosyal sorunların yaşanması da kaçınılmaz bir durumdur (Tınaz, 2006: 25).

Mobbingin örgütler açısından muhtemel olumsuz etkileriyle birlikte, örgüte olan bağlılığı ve yöneticiye olan güveni azaltması gerçekleşmesi beklenen bir durum olarak ortaya çıkacaktır. Mobbing kavramının işletmeler için gittikçe artan öneminin yanı sıra, özellikle yöneticiye güven konusuyla çok fazla doğrudan araştırma bulunmadığı tespit edilerek, çalışmanın konusu mobbingin örgüte bağlılık ve yöneticiye güven ile olan ilişkilerinin araştırılması olarak belirlenmiştir. Özellikle "yöneticiye güven ve mobbing" arasındaki doğrudan ilişkileri araştıran çalışmaların eksikliğinden dolayı, bu çalışmanın ilgili alan yazına katkı sağlayacağına inanılmaktadır. Bu bağlamda ilk olarak literatür taraması yapılarak, akabinde gerçekleştirilen analizler ve bu analizlerden elde edilen bulgu ve yorumlara yer verilmiştir.

\section{Kavramsal Çerçeve}

\subsection{Mobbing}

"Mobbing" kavramı biyologlar tarafından ilk olarak 19.yüzyılda kuşların, potansiyel tehdit olarak gördüğü diğer kuşların etrafında dolaşarak yuvalarını korumasını açıklamak amacıyla kullanılmıştır (Kara, Kim ve Uysal, 2018: 1453). 1960'larda ise Lorenz tarafından küçük hayvan gruplarının, daha büyük ve tek bir hayvanı dışlamak ve gruptan uzaklaştırmak üzere toplu şekilde hücum etmelerini ifade etmek için kullanılmıştır (Laleoğlu ve Özmete, 2013: 11). Lorenz'den sonra "mobbing" terimini 1972 yılında Heinemann, çocukların birbirleriyle olan iletişimleri üzerinden açıklamış ve gruplaşan çocukların tek bir çocuğu hedef alıp, zarar vermesini tanımlamak üzere kullanmıştır. 1980'lerin başında ise Leymann bu kavramı iş hayatına adapte etmiştir (Mimaroğlu ve Özgen, 2007: 204). Leymann'a göre mobbing, bir ya da birkaç kişi tarafından sistematik olarak ve çoğunlukla bir bireye doğru yönlendirilen düşmanca ve etik olmayan iletişim anlamına gelir (Leymann, 1990: 120). Başka bir tanıma göre mobbing; örgütü oluşturan bireyler arasındaki farklılıklar, amaçlar, faydalar nedeniyle ortaya çıkan bir çatışma şekli olarak ifade edilebilir (Koç ve Kurtbaş, 2011: 17). Leymann, mobbingi toplamda 45 ayrı davranıştan oluşan 5 boyutta kategorize etmiştir; mobbing mağdurunun kendini göstermesine ve iletişimine yönelik saldırılar, sosyal ilişkilerine saldırılar, itibarına saldırılar, yaşam kalitesine ve meslek durumuna saldırılar, sağııı̆̆ına saldırılar (Leymann, 1996: 170).

İş yerinde bir davranışın mobbing olarak adlandırılması için eylemin sık olarak (en azından haftada 1) ve uzun süre boyunca (en az 6 ay) gerçekleştiriliyor olması gereklidir (Leymann, 1996: 168) ve iş yerinde mobbing "tartışma, agresif eylemler, psikolojik saldırılar, "deli" olarak etiketleme ve istifa etmesini ya da kovulmasını sağlama" şeklinde 5 aşamalı bir süreçten oluşmaktadır (Koç ve Kurtbaş, 2011: 17). Bazı yazarlar ise; davranışlar daha az sıklıkla meydana geliyor olsa bile, hatta bazen belli bir zaman süresi olmaksızın da mobbing olabileceğini ifade etmektedirler (Zapf vd., 2010). Bunun yanısıra mobbing; örgütün her kademesinde meydana gelebilecek bir durumdur (Branch, Ramsay ve Barker, 2013: 281).

Mobbing davranışlarının sıklığı ve uzun bir süre boyunca devam ediyor olması mobbing mağdurunda ruhsal, duygusal ve davranışsal olarak (Kara, Kim ve Uysal, 2018: 1454) önemli psikolojik ve psikosomatik sonuçlara yol açmaktadır (Leymann, 1996: 168). Mobbing; küçük düşme, aşağılanma, mesleki itibar kaybı gibi durumlarla sonuçlanabilir (Duffy ve Sperry: 398). Bunun yanısıra diğer çalışanları da olumsuz etkilemektedir (Yüksel ve Tunçsiper, 2011: 56). Mobbing 
sebebiyle işgörenlerin bağlılığı ve sadakat duyguları yok olur, sıklıkla iş yerinden uzaklaşma ihtiyacı hissederler, tedavi giderleri artar ve iş verimlilikleri düşer, böylece örgüte olan maliyetleri de yükselir ve örgütte gerilimli bir iklim meydana gelir (Tutar, 2004: 114).

İş yerinde mobbingle mücadele etmek için en önemli husus gerekli farkındalığın sağlanmış olmasıdır. Mobbingi durdurmak ya da önlemek için iş yerindeki herkes bir şeyler yapmalıdır. Mobbingle ilgili farkındalığı arttırmak içinse; yaşanan sürecin adının konması, gerekli önlemlerin alınması, bilgilendirmenin yapılması ve geri bildirim alınması mühimdir (Tınaz, 2006: 26; Tetik, 2010: 86-87).

\section{2. Örgüte Bağlılık}

Örgüte bağlılık genel anlamıyla kişinin kurumsal amaçları kabul ederek bu amaçların gerçekleşmesi doğrultusunda çaba sarf etmesi ve kurumda kalmaya devam etme arzusudur (Durna ve Eren, 2005: 211). Başka bir ifadeyle bireyin kurumda kalma isteği ile örgütün amaç ve değerlerine bağıı olmasıdır. Örgüte bağlılık için Meyer ve Allen (1984) tarafından geliştirilen model oldukça kabul görmektedir. Bu modele göre, örgüte bağııık 3 bileşenden oluşan bir yapıdır ve "duygusal bağ|ılık, normatif bağ|ılık ve devam bağ|ılı̆ıı" alt boyutlarından meydana gelmektedir (Çekmecelioğlu, 2006: 155; Meyer ve Allen, 1984: 373-378).

Örgüte bağlılık ile ilgili yapılan ilk araştırmalar örgüte bağlılı̆ı tek boyutlu olarak ortaya koysa da, Meyer ve Allen bu kavramın 3 boyutlu yapıda olduğunu ortaya koymuşlardır (Yıldız, 2013: 855). Allen ve Meyer'e göre örgüte bağııık, genellikle, çalışan ve kuruluş arasında, çalışanın kuruluştan gönüllü olarak ayrılmasını daha az olası kılan psikolojik bir bağlantı olarak tanımlanabilir. Çalışanlar ve örgütleri arasındaki bu psikolojik bağlantı her biri ayırt edici tanımlamaya sahip olan 3 türden oluşmaktadır. Duygusal bağ|ılık, örgütle özdeşleşme ve örgüte duygusal olarak bağlanma anlamına gelir. Böylece güçlü duygusal bağlılığa sahip çalışanlar örgütte kendi istedikleri için kalmaktadırlar. Duygusal bağlılığa sahip çalışanlar örgüte karşı olumlu tutum sergilemektedirler ve gerektiğinde ek çalışma göstermeye gönüllüdürler. Devam bağlılığı, çalışanın örgütten ayrılması durumunda katlanacağı maliyetin farkında olmasına dayalı bağlılık türüdür. Örgüte devam bağ|ılı̆̆ yüksek bir kişi örgütten ayrılması durumunda daha az seçeneği olacağını düşünmektedir, bu yüzden de örgütte kalmaya devam etmektedir. Normatif bağlılık ise, örgüte karşı yükümlülük duygusuna dayanan bağlılık çeşididir. Güçlü normatif bağlılığa sahip çalışanlar örgütte kalmaları gerektiğini düşündükleri için örgütte kalırlar. Bir bakımdan bu kişiler örgütte minnettarlık duygusu sonucu kalırlar. Görüldüğü gibi, her üç bağ|ılık unsuru da bir örgütte kalmakla ilgili sonuçlara sahiptir, fakat bunun ötesinde kavramsal olarak oldukça farklıdır (Allen ve Meyer, 1996: 252-253; Bayram, 2005: 132-133). Daha kısa bir ifadeyle; duygusal bağılığa sahip kişi örgütte kalma isteğiyle (arzu), devam bağlılığına sahip kişi örgütte kalması gerektiği düşüncesiyle (ihtiyaç), normatif bağıılığa sahip kişi ise örgütte kalmak zorunda olduğu fikriyle (yükümlülük) örgütte kalmaktadır (Durna ve Eren, 2005: 212; Allen ve Meyer, 1991: 61).

Örgüte bağlılığı yüksek çalışanlar, örgütlerin hedeflerine ulaşmaları için kritik öneme sahiptir. Örgüte bağlılı̆̆ yüksek işgörenler görevlerini yerine getirmede ve örgüt hedeflerine ulaşmada ekstra çaba harcamaktadırlar. Bu sebeple, tüm örgütler çalışanlarının bağlılık düzeylerini arttırmak istemektedirler (Bayram, 2005: 137).

\subsection{Yöneticiye Güven}

Güven kavramıyla ilgili literatürde çeşitli tanımlamalar yapılmıştır. Rotter (1967)’a göre güven, bir birey ya da grubun söylediği kelimelere, sözlü ya da yazılı yaptığı beyanlara, başka bir birey ya da grubun itimat etmesi anlamına gelir (Rotter, 1967: 651). Buttler ve Cantrell (1984)'e 
göre ise; karşı tarafın davranışlarının doğru, tutarlı, güvenilir ve açık olacağına dair sahip olunan beklentidir (Buttler ve Cantrell, 1984). Başka bir tanımlamayla bireyin ya da bireylerin, verdikleri sözler doğrultusunda hareket edeceklerine, müzakerelerde dürüst olacaklarına, fırsatları varken bile faydacı davranmayacaklarına yönelik inançtır (Bromiley ve Cumings, 1992). Mayer, Davis ve Schoorman (1995)'ın tanımına göre; bir tarafın, doğrudan denetleyemediği, gözlemleyemediği ve çıkarlarıyla ilişkili konularda, kendinden beklenildiği şekilde davranacağı konusunda diğer tarafa karşı gönüllü olarak savunmasız hale gelmesidir (Mayer, Davis ve Schoorman, 1995: 712). Bu tanımlamaya göre; güvenen kişi, diğer tarafın aldığı kararlarda kendisi açısından önemli sonuçlara yol açabilecek ya da çıkarlarını etkileyebilecek davranış ve kararlara bağımlı olduğundan, karşı tarafın onun çıkarlarını da gözeterek karar alacağına inanmak durumundadır (Kalemci Tüzün, 2007: 96).

Güvenin, örgütsel yaşamdaki etkilerini inceleyen araştırmalarda genellikle; "çalışanlar arası güven, yöneticiye duyulan güven ve kurum olarak örgüte duyulan güven" şeklinde 3 tür güven öne çıkmaktadır. Çalışan, yöneticisini örgütle resmi bağlantısı olarak görmektedir ve böylece yöneticisine duyduğu güveni tüm örgüte yayma eğilimindedir (Durdağ ve Naktiyok, 2011; Tan ve Tan, 2000).

\section{Hipotez Geliştirme}

\subsection{Mobbing ve Örgüte Bağlılık Arasındaki İlişki}

İş yerindeki psikolojik taciz ile örgüte bağılık arasındaki ilişkiler incelendiğinde, bu iki olgu arasında kuvvetli bir ilişkiden söz edilebilmektedir. Kişilerin çalıştıkları örgütlerde yaşadıkları psikolojik taciz vakaları, örgüte karşı bağlıı̆ın azalmasında önemli bir etkendir (Yılmaz vd., 2008: 48). Örgütler içerisinde yaşanan psikolojik taciz vakaları hem örgütün verimliliğini hem de çalışanların iş tatminini olumsuz etkilemektedir. Yaşanan süreçlerin sonunda mağdurların içine çekildiği var olma savaşı, örgütlerin ve çalışanların amaç ve hedeflerinden uzaklaşmasına ve örgüt içindeki takım çalışmasının zorlaşmasına neden olacak ve sonuçta ciddi bir güvensizlik ortamı yaratacaktır (Tınaz 2006: 163). Örgüte bağlılığı negatif yönde etkilenen işgörenlerin, böylesi bir güvensizlik ortamında, özellikle duygusal bağ|ılık boyutunda zarar gördükleri izlenmektedir (Karcıoğlu ve Çelik 2012: 64).

Örgüte bağlılığı etkileyen önemli etkenlerden biri de iş tatmini duygusudur. İş tatmininin yüksek olduğu örgütlerde, örgüte bağlılık düzeyinin yüksek olması beklenen bir sonuçtur. Mobbing mağdurlarının ve mobbinge tanıklık eden diğer işgörenlerin iş tatminlerinde ortaya çıkan azalma durumunun, örgüte bağlılık duygusunu da aynı şekilde etkilemesi kaçınılmazdır (Yılmaz vd., 2008).

Mobbing ve örgüte bağlııık arasındaki ilişkilerin incelendiği çalışmalar, bu iki kavramın genellikle birbirleriyle negatif ilişkili olduğunu göstermektedir. Sağlık çalışanları ile yapılan bir çaıışmada, çalışanlara yapılan psikolojik taciz sıklığı arttıkça, örgütsel bağlılık düzeyinin düştüğü; özellikle de duygusal ve normatif bağıılığın etkilendiği izlenmiştir (Yıldız ve diğ. 2013: 111). Banka çalışanlarıyla gerçekleştirilen başka bir araştırmada; mobbingin örgüte bağıılığın üç boyutundan özellikle duygusal bağlılığı olumsuz yönde etkilediği tespit edilmiştir (Karcıoğlu ve Çelik 2012: 72). Devlet memurlarının mobbing algısı üzerine yapılan bir çalışma, mobbing algısının örgüte bağlılığı olumsuz olarak etkilediği sonucundan yola çıkarak, kişisel ve kurumsal başarının da olumsuz etkileneceğini öngörmüştür (Naktiyok ve Polat 2016: 15). Özel hastanelerde yapılan bir çalışmaya göre ise, çalıştıkları kurumlarda uğradıkları ya da tanı̆̆ı oldukları psikolojik taciz 
vakaları sonucu, çalışanların kurumlarına karşı duygusal bağlııkları olumsuz etkilenirken, normatif bağlılığa dair hiçbir ilişki bulunamamıştır (Yüksel ve Tunçsiper 2011: 62). Mobbing ile örgütsel bağlılığa dair yapılan çalışmalarda zaman zaman değişik sonuçlarla karşılaşılsa bile, araştırmaların çoğu iki olgu arasında ters yönlü bir ilişki olduğunu göstermektedir. Bu bilgiler ışığında, aşağıdaki hipotezler geliştirilmiştir;

$H_{1 a}$ : İs yerinde maruz kalınan mobbing, duygusal bağlılık ile negatif ilişkilidir.

$H_{1 b}$ : İs yerinde maruz kalınan mobbing, devam bağlılığı ile negatif ilişkilidir.

$H_{1 c}$ : Iş yerinde maruz kalınan mobbing, normatif bağlıık ile negatif ilişkilidir.

\subsection{Mobbing ve Yöneticiye Güven Arasındaki İlişki}

Güven, ilişki içerisinde bulunulan bireylerin menfaatimizi gözeteceğine ya da en azından bize zarar vermeyeceğine dair duyulan inanç iken mobbing ise uygulanış şekli olarak başka bir bireye zarar verme niyetiyle yapılmaktadır (Ertürk, 2016: 50). Mobbinge maruz kalan çalışan, zamanla kendine olan güvenini kaybederek, genel bir kararsızlık içerisine düşer. Uygulanan mobbing ile çalışan, yönetime olan güvenini kaybeder ve bu süreçte mağdurun yaşadıklarına şahit olan bireyler, ileride kendilerinin de bu süreci yaşayabileceği endişesine kapılır. Böylece, çalışanlar arasındaki uyum bozulma eğiliminde olur ve güvensizliğin hâkim olduğu bir ortam oluşur. Yani; mobbing süreci örgütteki tüm tarafların güvenini zedeleyebilmektedir (Özen Çöl, 2008: 110; Durdağ ve Naktiyok, 2011: 18).

Literatürde mobbing ile yöneticiye güven arasındaki ilişkiyi doğrudan araştıran çok fazla çaIışma bulunmamaktadır. Kaygın ve Atay tarafından (2014), mobbingin örgütsel güven ve örgütsel sessizlik ile olan ilişkisini belirlemeye yönelik Kars'ta gerçekleştirilen araştırmasında, mobbing ile örgütsel güven arasında anlamlı ve negatif ilişki olduğu, mobbingin 5 alt boyutundan 4'ünün (kendini gösterme ve iletişime yönelik saldırılar, sosyal ilişkilere yönelik saldırılar, itibara yönelik saldırılar, yaşam kalitesi ve mesleğe yönelik saldırılar), örgütsel güvenin alt boyutlarından olan yöneticiye güven ile anlamlı ve negatif yönde ilişkili olduğu bulgulanmıştır (Kaygın ve Atay, 2014: 103). Eşitti ve Akyüz tarafından (2015), Çanakkaledeki konaklama işletmeleri üzerinde gerçekleştirilen ve mobbing ile örgütsel güven ilişkisini araştıran çalışmada, mobbing ile örgütsel güvenin istatistiki olarak anlamlı ve negatif ilişkili olduğu tespit edilmişken, örgütsel güvenin alt boyutlarından biri olan yöneticiye güven ile mobbing arasında anlamlı bir ilişki tespit edilmemiştir (Eşitti ve Akyüz, 2005: 12). Buna karşın, Durdağ ve Naktiyok (2011) tarafından, Erzurumdaki devlet hastanelerinde çalışan hemşireler üzerinde yapılan çalışmada; çalışanların itibarına ve sosyal ilişkilerine saldırı biçimindeki mobbing, kendini gösterme ve iletişime saldırılar şeklindeki mobbing, mesleki konuma ve yaşam kalitesine saldırı şeklindeki mobbing ile yöneticiye güven arasındaki negatif ilişkileri belirlemeye yönelik kurulan tüm hipotezler kabul edilmiştir. Yani, söz konusu çalışmaya göre; mobbing ile yöneticiye güven arasında istatistiki olarak anlamlı ve ters yönlü bir ilişki bulunmaktadır (Durdağ ve Naktiyok, 2011). Bu bilgiler ışığında, aşağıdaki hipotez geliştirilmiştir;

$\mathrm{H}_{2}$ : Iş yerinde maruz kalınan mobbing, yöneticiye güven ile negatif ilişkilidir. 


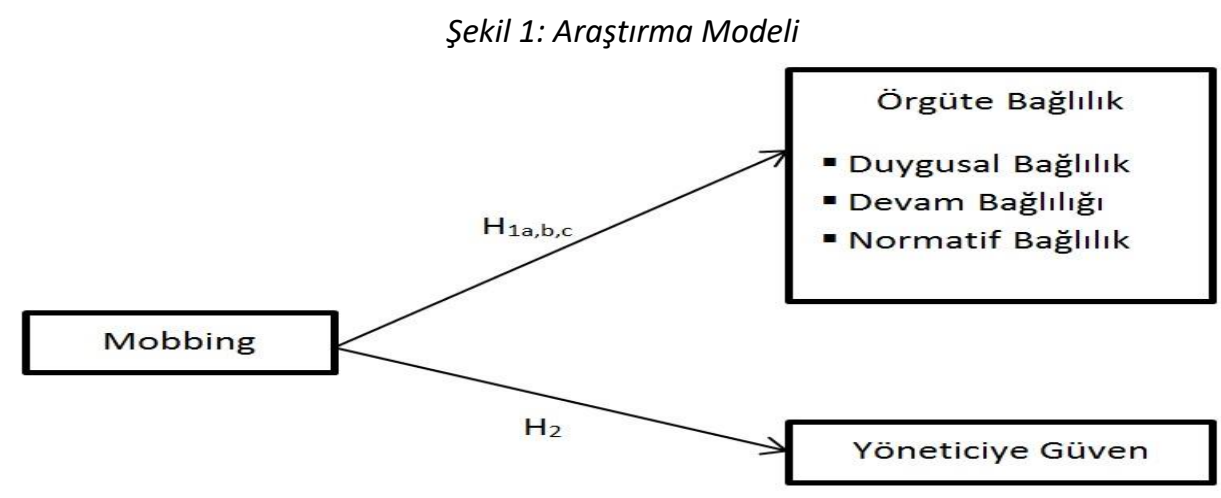

\section{Araştırma Metodolojisi}

\subsection{Araştırmanın Amacı ve Örneklem}

Bu araştırmanın amacı çalışanların mobbinge maruz kalmalarının örgüte bağılıklarıyla ve yöneticilerine güvenleriyle olan ilişkisini tespit etmektir. Araştırmanın örneklemini 7 farklı ilde kamu ve özel sektörde hizmet veren toplam 244 eğitimci oluşturmaktadır. Elde edilen sonuçların genellenebilirliğinin artması adına; 4 farklı bölgeden (Marmara Bölgesi: İstanbul, Bursa; İç Anadolu Bölgesi: Ankara, Konya; Akdeniz Bölgesi: Antalya, Hatay; Ege Bölgesi: İzmir) toplam 7 il seçilmiştir. Evreni temsil eden örneklem "basit tesadüfi örneklem" yöntemiyle tespit edilmiştir. Bu kapsamda, toplam 300 çalışana gönderilen anketlerden, geri dönüş yapan ve analize uygun olan 244 tane anket çalışma kapsamına alınmıştır.

Örneklemimizi oluşturan katılımcıların \%61.8'i kadındır ve katılımcıların \%67.9'u evlidir. 3337 yaş arasındaki kişiler, katılımcılarımızın \%32.1'ini oluşturmaktayken, 38-42 yaş arası \%23.6 ve $28-32$ yaş arası ise \%19.9'luk kısmını oluşturmaktadır. Katılımcıların \%74'ü lisans mezunudur. \%47.9 katılımcı 11-20 yıl arasında çalışmaktayken, \%37.8'inin çalışma süresi 10 yıldan azdır. Katılımcıların \%85'i öğretmen, \%7.7'si müdür yardımcısı ve \%6.5'i müdürdür.

\subsection{Veri Toplama Araçları}

Araştırmada veri toplama yöntemi olarak anket kullanılmıştır. Oluşturulan anketler için üç farklı ölçekten faydalanmıştır. İlk ölçek Allen ve Meyer'in geliştirdiği “Örgütsel Bağılıık Ölçeği (Organizational Commitment Questionnaire: OCQ)"dir. Kullanılan diğer ölçek, Pranjic ve arkadaşlarının (2006) geliştirdiği “Mobbing” ölçeğidir. Son ölçek ise; Podsakoff ve arkadaşları (1990) tarafından geliştirilen "Lidere Güven" ölçeğidir.

Her üç ölçekte de 5'li likert kullanılmış ve "1: Kesinlikle Katılmıyorum, 2: Katılmıyorum, 3: Kararsızım, 4: Katılıyorum, 5: Kesinlikle Katılıyorum” şeklinde derecelendirilmiştir.

\subsection{Verilerin Analizi ve Bulgular}

Araştırma verilerinin değerlendirilmesinde SPSS 23.0 istatistik paket programı kullanılmıştır. Veriler geçerlilik ve güvenilirlik analizleri ile korelasyon ve regresyon analizlerine tabi tutulmuştur.

\subsection{1 Ölçüm Geçerliliği ve Güvenilirliği}

Veriler toplandıktan sonra, veri setinin geçerliliği ve güvenilirliği test edilmiştir. Bu bağlamda, ilk olarak araştırma modelindeki değişkenlere açıklayıcı faktör analizi uygulanmıştır. Veri seti için KMO (Kaiser-Meyer-Olkin) örneklem yeterlilik değeri 0,932 olarak bulunmuş ve önerilen 0,50 değerinden yüksek olduğu tespit edilmiştir. Bununla birlikte, Barlett Küresellik testi ( $\chi 2$ 
$(703)=6191,159 ; p=0.00<0.01) 0.01$ anlamlılık düzeyinde istatistiki olarak anlamlıdır. Uygulanan açıklayıcı faktör analizinde; mobbing faktöründen 4 soru, duygusal bağlılık faktöründen 1 soru, devam bağ|ılığı faktöründen 1 soru ve normatif bağ|ılık faktöründen 1 soru, faktör yükleri 0.50 'nin altında olmasından dolayı analiz dışında bırakılmıştır. Elde edilen nihai faktör analizi sonucuna göre faktörler beklenilen şekilde 5 faktöre ayrılmış ve açıklanan toplam varyans oranı \%63.57 olarak bulunmuştur (Bkz. Tablo 1).

Tablo 1: Açıklayıcı Faktör Analizi Sonuçları

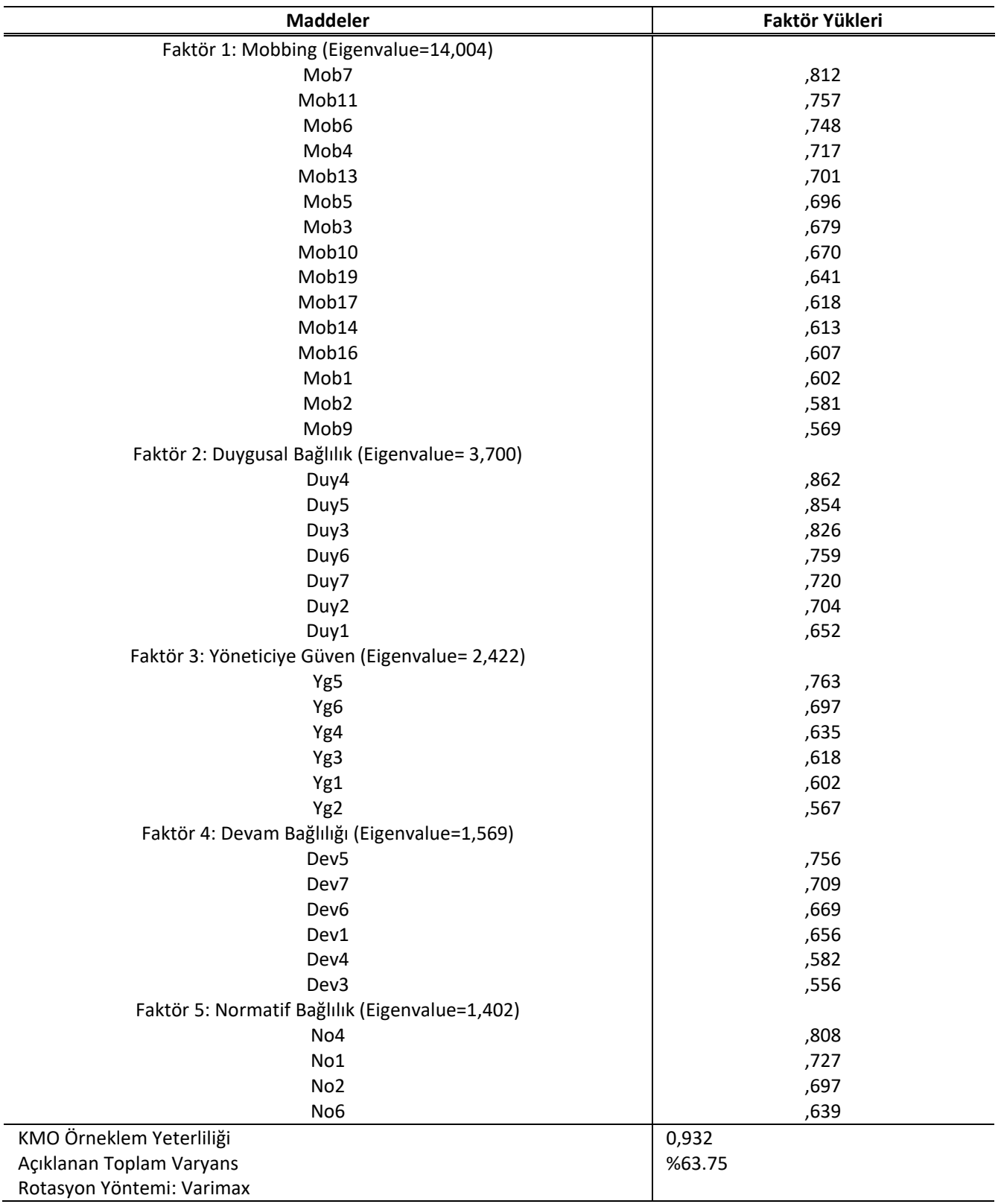


Faktör analizinin ardından, her faktör için ortalama ve standart sapmalar hesaplanmıştır ve Tablo 2'de gösterildiği gibi korelasyon matrisi oluşturulmuştur (Bkz. Tablo 2). Tüm faktörler için hesaplanan Cronbach Alpha güvenilirlik katsayısı, kabul edilen asgari değer olan 0,70'in (Nunnaly, 1978) üzerinde olduğundan (Mobbing; ,778; Yöneticiye Güven: ,937; Duygusal Bağlılık: ,894; Devam Bağııı̆̆ı: ,939; Normatif Bağ|ılık: ,768) kullanılan ölçeklerin güvenilir olduğu ifade edilebilir.

Tablo 2: Güvenilirlik, Korelasyon ve Tanımlayıcı Istatistikler Tablosu

\begin{tabular}{|c|c|c|c|c|c|c|c|c|}
\hline & Ortalama & $\begin{array}{c}\text { Standart } \\
\text { Sapma }\end{array}$ & $\begin{array}{c}\text { Cronbach } \\
\text { Alpha }\end{array}$ & M & YG & Duy & Dev & $\mathbf{N}$ \\
\hline Mobbing & 2,2172 & 76005 & $\alpha=, 778$ & 1 & & & & \\
\hline Yöneticiye Güven & 3,2384 & ,87853 & $\alpha=, 937$ &,$- 667^{* *}$ & 1 & & & \\
\hline Duygusal Bağlılık & 3,4374 & 94228 & $\alpha=, 894$ &,$- 592^{* *}$ &, $691^{* *}$ & 1 & & \\
\hline Devam Bağlılığı & 2,8347 & ,78698 & $\alpha=, 939$ &, $304^{* *}$ &,- 076 &,$- 179^{* *}$ & 1 & \\
\hline Normatif Bağlılık & 3,1609 & ,89695 & $\alpha=, 768$ &,$- 244^{* *}$ &, $421^{* *}$ & $466^{* *}$ & 120 & 1 \\
\hline
\end{tabular}

\subsubsection{Hipotez Testleri}

Araştırma hipotezlerini test etmek için SPSS programı ile regresyon analizleri uygulanmıştır. İlk olarak, örgüte bağlılığın alt boyutu ile mobbing arasındaki negatif yönlü ilişkilere (Bkz. Tablo 3), sonrasında yöneticiye güven ile mobbing arasındaki negatif yönlü ilişkiye bakılmıştır (Bkz. Tablo 4). Elde edilen sonuçlara göre Model $1\left(R^{2}=, 351 F=130,686 ; R^{2}=, 092 F=24,556 ; R^{2}=, 060\right.$ $F=15,364)$ ve Model $2\left(R^{2}=, 445 F=194,362\right)$ anlamlıdır.

Hipotez testlerinden elde edilen bulgulara göre; i-) mobbing ile duygusal bağlılık arasında istatistiki olarak anlamlı ve ters yönlü ( $\beta=-, 592$; Sig=, 000$)$, ii-) mobbing ile normatif bağlılık arasında istatistiki olarak anlamlı ve ters yönlü $(\beta=-, 224$; Sig=,000) ve iii-) mobbing ile yöneticiye güven arasında istatistiki olarak anlamlı ve ters yönlü $(\beta=-, 667$; Sig=,000) ilişkiler tespit edilmiştir. Ancak; mobbing ile devam bağıılığı arasında ters yönlü $(\beta=, 304)$ bir ilişki saptanamamıştır. Elde edilen bu bulgular dahilinde; $\mathrm{H}_{1 \mathrm{~b}}$ hipotezi red edilirken, $\mathrm{H}_{1 \mathrm{a}}, \mathrm{H}_{1 \mathrm{c}}$ ve $\mathrm{H}_{2}$ hipotezleri kabul edilmiştir.

Tablo 3: Regresyon Analizi Sonucu - Örgüte Bağlılığın Alt Boyutları ile Mobbing Arasındaki ilişski

\begin{tabular}{|c|c|c|c|c|c|c|}
\hline Model-1 & \multicolumn{6}{|c|}{ Bağımlı Değişkenler } \\
\hline Bağımsız Değişken & \multicolumn{2}{|c|}{ Duygusal Bağlılık } & \multicolumn{2}{|c|}{ Devam Bağlılığı } & \multicolumn{2}{|c|}{ Normatif Bağlılık } \\
\hline \multirow{4}{*}{ Mobbing } & $\beta$ & Sig. & $\beta$ & Sig. & $\beta$ & Sig. \\
\hline &,- 592 & ,000 & ,304 & ,000 &,- 244 & ,000 \\
\hline & \multicolumn{2}{|c|}{$F=130,686$} & \multicolumn{2}{|c|}{$F=24,556$} & \multicolumn{2}{|c|}{$F=15,364$} \\
\hline & \multicolumn{2}{|c|}{$R^{2}=, 351$} & \multicolumn{2}{|c|}{$R^{2}=, 092$} & \multicolumn{2}{|c|}{$R^{2}=, 060$} \\
\hline
\end{tabular}


Tablo 4: Regresyon Analizi Sonucu - Yöneticiye Güven ile Mobbing Arasındaki Ilişski

\begin{tabular}{|c|c|c|}
\hline Model-2 & \multicolumn{2}{|c|}{ Bağımlı Değişken } \\
\hline Bağımsız Değişken & \multicolumn{2}{|c|}{ Yöneticiye güven } \\
\hline \multirow{4}{*}{ Mobbing } & $\beta$ & Sig. \\
\hline &,- 667 & 000 \\
\hline & \multicolumn{2}{|c|}{$F=194,362$} \\
\hline & \multicolumn{2}{|c|}{$R^{2}=, 445$} \\
\hline
\end{tabular}

Devam bağlılığı ile mobbing arasında beklendiği şekilde anlamlı ve ters yönlü bir ilişki gözlenmemesinin bir sebebi Türkiye'deki işsizlik oranları olabilir. Daha önce açıklandığı üzere, devam bağlılı̆ı; çalışanın örgütten ayrılması durumunda katlanacağı maliyetin farkında olmasıyla ortaya çıkan bir bağlılık türüdür. Bu türden bağlılığı yüksek olan bir kişi, çalıştığı örgütten ayrılması halinde, seçeneklerinin az olduğunu düşünerek, örgütte kalmaya devam etmektedir. Bununla birlikte, Türkiye'de güncel olarak işsizlik oranları, yükselme eğilimindedir. Temmuz 2019 verilerine göre, bir önceki yıla oranla işsizlik 1.000.065 kişilik artış ile, \%13,9'a yükselmiştir (TUiK, 2019). Böyle bir ekonomik tabloda, çalışanlar mobbinge uğrasa bile, çalıştığı örgütten ayrılması halinde katlanacağı maliyetin farkında olduklarından dolayı, devam bağlılıkları mobbingten negatif olarak etkilenmemiş olabilir. Bununla birlikte, örneklemimizin çoğunluğunu (\%85) öğretmenler oluşturmaktadır. Öğretmenlerdeki işsizlik oranlarının da yıllar bazında arttığı ifade edilebilir. 2003 yılında işsiz öğretmen oranı \%85,96 iken, 2016 yılında bu oran \%94,45 olarak gerçekleşmiştir (Kiraz ve Kurul, 2018: 273). Dolayısıyla, öğretmenler işsiz kalma korkularından dolayı, mobbinge uğrasalar dahi, devam bağılıkları bundan etkilenmemiş olabilir. Ancak, aynı araştırma farklı bir meslek grubundaki kişilere uygulanırsa, bu sonuçlardan farklı sonuçlar elde edebilmek de mümkündür.

\section{Tartışma ve Sonuç}

Bu çalışmada, çalışanların maruz kaldıkları mobbing davranışları ile örgüte bağlııkları ve yöneticiye güvenleri arasındaki ilişkiler incelenmiştir. Yapılan araştırma neticesinde, mobbingin örgüte bağ|ılığın alt boyutlarından olan "duygusal bağ|ılık" ve "normatif bağ|ılık" ile istatistiki olarak anlamlı ve negatif ilişkili olduğu, aynı şekilde mobbingin yöneticiye duyulan güven ile de istatistiki olarak anlamlı ve negatif ilişkili olduğu bulgulanmıştır. Mobbing ve örgüte bağııık ile ilgili elde edilen bulgular, Yıldız ve diğerlerinin (2013) sağlık çalışanları üzerinde gerçekleştirdiği ve özellikle duygusal ve normatif bağlılı̆ın mobbing ile negatif ilişkili olduğunun belirlendiği çaIışması ile uyumludur. Karcıoğlu ve Çelik tarafından (2012) gerçekleştirilen araştırmada elde edilen, mobbingin "duygusal bağ|ılık" ile negatif ilişkili bulunduğu çalışma ile de "duygusal bağ|ılık" alt boyutu açısından uyum göstermektedir. Araştırmamız, Yüksel ve Tunçsiper (2011) tarafından özel hastanelerde gerçekleştirilen çalışmanın, "duygusal bağlıık" ile ilgili sonucuyla aynı doğrultudayken, ilgili araştırmada "normatif bağlıık" ile ilgili anlamlı ilişki tespit edilmemiştir. Bu bağlamda çalışmamız Yüksel ve Tunçsiper'in mobbing ile ilgili "normatif bağlılık" sonucuyla aynı doğrultuda olmayan sonuçlar göstermektedir.

Araştırmamızın bir diğer sonucu, daha önce belirtildiği üzere, mobbing ile yöneticiye güven arasında tespit edilen istatistiki olarak anlamlı ve negatif ilişkidir. Bu sonuç dikkate alındığında, araştırmamız Kaygın ve Atay (2014) tarafından gerçekleştirilen ve mobbingin 5 alt boyutundan 4'ünün yöneticiye güven ile anlamlı ve negatif ilişkili bulunduğu çalışmasıyla ve Durdağ ve Naktiyok (2011) tarafından gerçekleştirilen, mobbing ile yöneticiye güven arasında istatistiki olarak 
anlamlı ve negatif ilişkileri ortaya koyan çalışmasıyla uyum göstermekteyken, Eşitti ve Akyüz (2005) tarafından gerçekleştirilen ve mobbing ile yöneticiye güven arasında istatistiki olarak anlamlı bir ilişki tespit edilemeyen araştırmasıyla farklı sonuçlar göstermektedir.

Çalışmadan elde edilen bulgular neticesinde, bu konuda araştırma yapmak isteyen araştırmacılara ve yöneticilere bazı önerilerde bulunabilir. Çalışmamızdan elde edilen bulgular ve önceki çalışmalardan elde edilen bulguların genelleştirilmesi açısından; mobbing, örgüte bağlılık ve yöneticiye güvenle ilgili farklı sektörlerde araştırmalar yapılabilir. Örgüte bağlılığın alt boyutları olan "duygusal bağlılık", "normatif bağlılık" ve "devam bağlı̆̆ı"nın hangisinin mobbingten daha fazla etkilendiği ve bunun olası sebepleri üzerine daha spesifik bir araştırma gerçekleştirilebilir. Bununla birlikte, mobbing ve yöneticiye güven arasındaki doğrudan ilişkilerin araştırıldığı çalışmalara literatürde çok fazla rastlanmamıştır, dolayısıyla bu iki konuda yapılacak diğer çalışmalar da, araştırmaların farklı sektörel ve kültürel bağlamlarda yapılmasıyla birlikte, sonuçların genellenebilirliğini arttırarak alan yazının gelişmesine katkı sağlayacaktır.

Günümüzde örgüte bağlılı̆ı yüksek çalışanlar, örgütün sürdürülebilirliği, rekabet avantajı elde etmesi, amaç ve hedeflerine ulaşma başarısı açısından çok önemli bir faktör olarak görülmektedir. Araştırmamızdan elde ettiğimiz sonuçlar da mobbingin, çalışanların örgüte bağıııklarını ve yöneticiye olan güvenlerini azalttığını ortaya koymaktadır. Dolayısıyla yöneticiler, örgüte bağlılıkları yüksek olan çalışanlarla, örgütlerine artı değer kazandırmak için mobbing davranışını azaltacak ve hatta engelleyecek uygulamalar gerçekleştirmelidirler. Bunun için en önemli nokta, örgütte gerekli farkındalığın sağlanmış olmasıdır. Yöneticiler de bu noktada mobbingle ilgili farkındalığı sağlamak için çaba harcamalıdırlar. Bunun içinse; yaşanan sürecin adının konması, gerekli bilgilendirmelerin yapılması ve geri bildirimlerin sağlanması mühimdir.

Çalışmamızın elbette bazı sınırlılıkları vardır. Anketle veri toplamanın zorluğu ve dağıtılan tüm anketlere dönüş alınamaması, bununla birlikte çalışmanın belli illerde gerçekleştirilmesi çalışmanın sınırılıklarıdır. Ayrıca, örneklemin eğitimcilerden oluşması da bir başka sınırlılık olarak ifade edilebilir. 


\section{Kaynaklar}

Allen, Natalie J; Meyer, John P., (1996), "Affective, continuance, and normative commitment to the organization: An examination of construct validity." Journal of Vocational Behavior, Vol. 49, No.3: 252-276.

Bayram, Levent. (2005), "Yönetimde Yeni Bir Paradigma: Örgütsel Bağlılık”, Sayıştay Dergisi, No.59: 125-139.

Bedük, Aykut; Yıldız, Esra, (2016), “Mobbing (psikolojik şiddet) ve örgütsel bağlılık ilişkisi: Hastane çalışanlarına yönelik bir uygulama", Sosyal ve Ekonomik Araştırmalar Dergisi, Vol.18, No.31: 77-87.

Branch, S.; Ramsay, S., \& Barker, (2013), “Workplace Bullying, Mobbing and General Harassment: A Review”, International Journal of Management Reviews, Vol.15, No.3: 280-299.

Bromiley, Philip; Cummings, Larry L., (1992), "Transactions costs in organizations with trust", Minneapolis: Strategic Management Research Center, University of Minnesota.

Butler Jr, John K; Cantrell, R. Stephen., (1984), "A behavioral decision theory approach to modeling dyadic trust in superiors and subordinates", Psychological Reports, Vol.55, No.1: 19-28.

Çekmecelioğlu, Hülya, (2006), “iş tatmini ve örgütsel bağlılık tutumlarının işten ayrılma niyeti ve verimlilik üzerindeki etkilerinin değerlendirilmesi: Bir araştırma”, ISGUC The Journal of Industrial Relations and Human Resources, Vol.8, No.2: 153-168.

Duffy, M., \& Sperry, L. (2007), “Workplace mobbing: Individual and Family Health Consequences”, The Family Journal, Vol.15, No.4: 398-404.

Durdağ, Fatma Merve; Naktiyok, Atılhan, (2011), “Psikolojik taciz algısının örgütsel güven üzerindeki rolü”, Kafkas Üniversitesi iiBF Dergisi, Vol.1, No.2: 5-37.

Durna, Ufuk; Eren, Veysel, (2005), "Üç bağlılık unsuru ekseninde örgütsel bağlılık”, Doğuş Üniversitesi Dergisi, Vol.6, No.2: 210-219.

Eşitti, Bekir; Akyüz, Bülent, (2015), “Konaklama İşletmelerinde Mobbing-Örgütsel Güven İlişkisi: Çanakkale İlinde Bir Araştırma”, Selçuk Üniversitesi Sosyal Bilimler Enstitüsü Dergisi, Vol.34: 1-14.

Ertürk, Abbas, (2016), “Organizational trust of mobbing victims: a study of turkish teachers", Journal of Education and Training Studies, Vol.4, No.11: 49-57.

Kalemci Tüzün, İpek, (2007), “Güven, örgütsel güven ve örgütsel güven modelleri”, Karamanoğlu Mehmetbey Üniversitesi Sosyal Ve Ekonomik Araştırmalar Dergisi, Sayı:2, 93-118.

Kara, Derya; Kim, Hyelin; Uysal, Muzaffer, (2018), “The effect of manager mobbing behaviour on female employees' quality of life", Current Issues in Tourism, Vol. 21, No.13: 1453-1467.

Karcıoğlu, Fatih; Çelik, Ülke, (2012), "Mobbing (yıldırma) ve örgütsel bağlılığa etkisi”, Atatürk Üniversitesi iktisadi ve idari Bilimler Dergisi, Vol.26, No.1: 59-75.

Kaygın, Erdoğan; Atay, Metin, (2014), “Mobbingin örgütsel güven ve örgütsel sessizliğe etkisi-Kamu kurumunda bir uygulama", Çukurova Üniversitesi Iktisadi ve Idari Bilimler Fakültesi Dergisi, Vol.18, No.2: 95-113.

Kiraz, Z., \& Kurul, N. (2018), Türkiye'de Öğretmen İşsizliği ve Ataması Yapılmayan Öğretmenler Hareketi, Mersin Üniversitesi Eğitim Fakültesi Dergisi, Vol.14, No.1, 270-302.

Koç, Hakan; Kurtbaş, Demet, (2011), "The Relationship between Mobbing the Academics are exposed to and the Organizational Commitment: A Study in the public and private universities", International Journal of Academic Research in Accounting, Finance and Management Sciences, Vol.1, No.2: 16-32.

Laleoğlu, Ayşegül; Özmete, Emine, (2013), “Mobbing Ölçeği: Geçerlik ve Güvenirlik Çalışması”, Sosyal Politika Çalışmaları Dergisi, Vol.7, No.31: 9-31.

Leymann, Heinz, (1996), "The content and development of mobbing at work", European Journal of Work and Organizational Psychology, Vol.5, No.2: 165-184.

Mayer, Roger; Davis, James H.; Schoorman, F.David, (1995), “An Integrative Model Of Organizational Trust”, Academy of Management Review, Vol. 20, No.3: 709-734.

Meyer, John P.; Allen, Natalie J., (1984), "Testing the" side-bet theory" of organizational commitment: Some methodological considerations", Journal of Applied Psychology, Vol.69, No.3: 372-378.

Meyer, John P.; Allen, Natalie J., (1991), “A three-component conceptualization of organizational commitment”, Human Resource Management Review, Vol.1, No.1: 61-89.

Mimaroğlu, Hande; Özgen, Hüseyin, (2007), “Örgütlerde Güncel Bir Sorun:“Mobbing” ”, Sosyal Ekonomik Araştırmalar Dergisi, Vol.8, No.15: 201-226. 


\section{Eskişehir Osmangazi Üniversitesi ïiBF Dergisi}

Naktiyok, Atılhan; Polat, Fatma, (2016), “Çalışanların Psikolojik Taciz Algısının Örgütsel Bağlılıkla Illişkisi”, Atatürk Üniversitesi Iktisadi ve Idari Bilimler Dergisi, Vol.30, No.1: 1-17.

Nunnaly, Jum (1978), Psychometric Theory, New York: McGraw-Hill.

Özen Çöl, Serap, (2008), "İşyerinde psikolojik şiddet: Hastane çalışanları üzerine bir araştırma”, Çalışma ve Toplum Dergisi, Vol.4: 107-134.

Rotter, Julian B., (1967), “A new scale for the measurement of interpersonal trust”, Journal of personality, Vol.35, No.4: 651-665.

Tan, Hwee Hoon; Tan, Christy S., (2000), "Toward the differentiation of trust in supervisor and trust in organization", Genetic, Social, and General Psychology Monographs, Vol.126, No.2: 241-260.

Tetik, Semra, (2010), "Mobbing kavramı: Birey ve örgütler açısından önemi”, Karamanoğlu Mehmetbey Üniversitesi Sosyal ve Ekonomik Araştırmalar Dergisi, Vol.1: 81-89.

Tınaz, Pınar, (2006), İsyerinde psikolojik taciz (mobbing).

Tutar, Hasan, (2004), “işsyerinde psikolojik şiddet sarmalı: nedenleri ve sonuçları”, Yönetim Bilimleri Dergisi, Vol.2, No.2. 101-128.

TÜiK, 2019.

Yıldız, Gültekin; Akbolat, Mahmut; Işık, Oğuz, (2013), “Psikolojik taciz ve örgütsel bağlılık: Sağlık çalışanları üzerine bir araştırma". Manas Sosyal Araştırmalar Dergisi, Vol.2, No.6: 85-112.

Yıldız, Kaya, (2013), “Örgütsel Bağlılık ile Örgütsel Sinizm ve Örgütsel Muhalefet Arasındaki İlişki”. Electronic Turkish Studies, Vol.8, No.6: 853-879.

Yılmaz, Abdullah; Özler, Derya Ergun; Mercan, Nuray, (2008), “Mobbing ve Örgüt İklimi İle İlişkisine Yönelik Ampirik Bir Araştırma”, Elektronik Sosyal Bilimler Dergisi, Vol.7, No.26: 334-357.

Yüksel, Murad; Tunçsiper, Bedriye, (2011), "The relationship between mobbing and organizational commitment in workplace", International Review of Management and Marketing, Vol.1, No.3: 54-64.

Einarsen, S., Hoel, H., Zapf, D., \& Cooper, C. (2010), "Bullying and harassment in the workplace: Developments in theory, research, and practice". Crc Press. 


\section{Extended Summary}

\section{The Effect of Mobbing on Organizational Commitment and Trust in Manager}

Mobbing, which is a serious problem that arises from the combination of factors leading to tension and conflict climate in the organization and disrupts the health of the organization and at the same time prevents the peace of work, is a systematic process in which the employees inside the organization disturb the other person or individuals and become immoral. In organizations where mobbing occurs, employees lose their trust and commitment feelings towards the organization. Mobbing has negative effects on the organization as well as on the person. The problems that arise may be economic at first for the manager. However, it is inevitable that there will be severe social problems.

Along with the possible negative effects of mobbing for organizations, it is expected that this will decrease the commitment to the organization and the trust in the manager. In addition to the increasing importance of the concept of mobbing for businesses, it has been determined that there is not much direct research, especially with regard to trust in managers, and the subject of the study is to investigate the relationship between mobbing and organizational commitment and trust in managers. It is believed that this study will contribute to the relevant literature, especially due to the lack of studies investigating the direct relationships between trust in manager and mobbing.

When the relationships between mobbing and commitment to the organization are examined, a strong relationship can be mentioned between these two variables. Mobbing cases in the organizations are an important factor in decreasing the commitment to the organization. Studies examining the relationship between mobbing and commitment to the organization show that these two concepts are generally negatively related. Furthermore, the employee exposed to mobbing loses his/her self-confidence over time and falls into general indecision. By applying mobbing to the employee, the employee loses his/her confidence in the management and people who witness the experiences of the victim in this process are worried that they may also experience this process in the future. Thus, the harmony between employees tends to deteriorate and an environment of insecurity prevails. So, the mobbing process can damage the trust of all sides in the organization. In this context, the hypotheses of the study were determined as follows: $H_{1 a}$ : Mobbing at work is negatively related to affective commitment. $H_{1 b}$ : Mobbing at work is negatively related to continuance commitment. $H_{1 c}$ : Mobbing at work is negatively related to normative commitment. $H_{2}$ : Mobbing at work is negatively related to trust in manager.

The sample of the study consists of 244 educators serving in public and private sectors in 7 different provinces. In order to increase the generalizability of the results obtained, a total of 7 provinces were selected from 4 different geographical regions (Marmara Region: Istanbul, Bursa; Central Anatolia Region: Ankara, Konya; Mediterranean Region: Antalya, Hatay; Aegean Region: Izmir) in Turkey. The sample representing the universe was determined by the "simple random sample" method. In this context, 244 questionnaires, which were sent back to a total of 300 employees, which were returned and suitable for analysis, were included in the study.

In the research, a questionnaire was used as data collection method. It has benefited from three different scales for the created questionnaires. In all three scales, 5-point Likert was used and it was rated as "1: Strongly Disagree, 2: Disagree, 3: Undecided, 4: Agree, 5: Strongly Agree". SPSS 23.0 statistics package program was used to evaluate the research data. Data were subjected to validity and reliability analysis, and correlation and regression analysis.

According to the findings obtained from the hypotheses tests; $i-$ ) statistically significant and negative relationship between mobbing and affective commitment $(\beta=-, 592$; Sig $=, 000)$, ii-) statistically significant and negative relationship between mobbing and normative commitment $(\beta=-, 224$; Sig $=, 000)$ and, iii-) statistically significant and negative $(\beta=$ ,- 667 ; Sig $=, 000$ ) relationships were determined between mobbing and trust in the manager. But, no negative relationship $(\beta=, 304)$ was found between mobbing and continuance commitment. As a result of these findings; while $H 1 b$ hypothesis was rejected, $\mathrm{H} 1 \mathrm{a}, \mathrm{H} 1 \mathrm{c}$ and $\mathrm{H} 2$ hypotheses were accepted.

So, as a result of the research, it has been found that mobbing is statistically significant and negatively related with "affective commitment" and "normative commitment", which are sub-dimensions of commitment to the organization, and also mobbing is statistically significant and negatively related with the trust in the manager. However, contrary to expectations, no negative relationship could be detected between continuance commitment and mobbing. One of the reasons we've not found a negative relationship between mobbing and commitment can the unemployment rate in Turkey. Continuance commitment; it is a type of commitment that emerges when the employee is aware of the cost to bear if he/she leaves the organization. A person with a high level of continuance commitment continues to stay in the organization, considering that they do not have many options if they leave the organization they work for. In addition to this, in the current unemployment rate in Turkey tend to rise. According to the TUIK's (Turkish Statistical Institute) data of July 2019 , unemployment increased by 1.000 .065 persons compared to the previous year and reached 


\section{Eskişehir Osmangazi Üniversitesi iiBF Dergisi}

13.9\%. In such an economic situation, even if employees are exposed to mobbing, their continuance commitment may not be negatively affected by mobbing because they are aware of the cost they will incur if they leave the organization they work for. In addition to this, the majority of our sample (85\%) consists of teachers. It can be stated that unemployment rates in teachers also increased on a yearly basis. While the rate of unemployed teachers was $85.96 \%$ in 2003, this rate was $94.45 \%$ in 2016 . Therefore, even if they are exposed to mobbing, their continuance commitment may not be affected because of the fear of being unemployed. But, if the same research is applied to people in a different occupation group, it is possible to obtain different results from these results. 